\title{
LESSON 135
}

MARGINS: Pica, 12-72; Elite, 20-80.

\section{Improve Accuracy}

25 wpm 10 minutes.

A42 - SI 1.42

Test your Skill

10 minutes.

MARGINS: $25 \mathrm{~mm}$ ( 1 inch).

Keep the right margin as straight as possible.

Use double-line spacing.

$\mathrm{T} 30-\mathrm{S} 11.35$
We tend to take the Post Office for granted and fail to realize the part it plays in our daily lives until something goes wrong. We all like to receive letters from friends, to get 'phone calls and to watch television or to listen to the radio. All these things in part rely on the Post Office. A great many other services are provided as well as these more obvious ones and the services provided by the Post Office in this country come under distinct headings.

First there is the obvious one of communications. Then there is a whole range of social services, including payment of pensions and family allowances. The Post Office issues a great range of licences and these include television, radio, dog, game, game dealer licences and gamekeeper licences. If you want various forms to do with driving and taxing a motor vehicle, the Post Office is one place to go to for them. If you want to save money, gamble with it on Premium Bonds, pay a bill through Giro or buy money orders or postal orders you use the Post Office.

All too often, it is not until you want something which is slightly out of the ordinary that you realize just what a range of services the Post Office offers for the dispatch of parcels and letters. Just consider the letter range. There are the first and second class mail services for sending any letters in this country. You choose which service you want, and indicate your choice by the stamp you stick on. If your letter is going overseas you can choose to send it by air or by surface mail. If the letter is going by air then you use the special air letter form as a rule. If you wish, you may send the letter direct from certain air terminals either for collection at the country of destination or for posting when it arrives. This is called an airway letter.

If you want a letter taken at once and not have to wait for the normal post the Post Office offers you a wide choice of services. You may wish to use the messenger service when the letter is taken direct to the addressee by a messenger a rather expensive service. The railex service allows for a letter to be taken to a railway station to be taken by train to the town of destination for collection or for posting. A person who had missed the last post with an important letter would use this service. If you want proof of posting a good service to use is the recorded delivery service while if the package or letter contains things of value, registering your mail is a must.

The details of all the Post Office services are printed in the Post Office Guide and you can easily purchase this at the local main office of the Post Office. One of the jobs a young office worker might well have to do is keep the office copy of the Guide up-to-date by adding the monthly additions to it, issued free of charge. These monthly additions are a way of keeping the Guide up-to-date in the changing world. 